\title{
Experimentação didática visando o ensino de Geometria Analítica utilizando smartphones: uma adaptação do Projeto Reforço Escolar com o aplicativo GeoGebra
}

\author{
Didactic experimentation aiming at teaching Analytical Geometry using smartphones: an \\ adaptation of the School Reinforcement Project with GeoGebra app
}

\begin{abstract}
Nelson Machado Barbosa Universidade Estadual do Norte Fluminense (UENF), Laboratório de Ciências Matemáticas, Campos dos Goytacazes, RJ, Brasil https://orcid.org/0000-0002-0628-1195, barbosa@uenf.br
\end{abstract}

Érika da Costa Sant'Ana Universidade Estadual do Norte Fluminense (UENF), Laboratório de Ciências Matemáticas, Programa de Pós-Graduação Profissional em Matemática, Campos dos Goytacazes, RJ, Brasil (D) https://orcid.org/0000-0001-9056-3648, erikacsantana@yahoo.com.br

\begin{tabular}{l}
\hline Informações do Artigo \\
\hline Como citar este artigo \\
BARBOSA, Nelson Machado; SANT'ANA, \\
Érika da Costa. Experimentação didática \\
visando o ensino de Geometria Analítica \\
utilizando smartphones: uma adaptação do \\
Projeto Reforço Escolar com o aplicativo \\
GeoGebra. REMAT: Revista Eletrônica da \\
Matemática, Bento Gonçalves, RS, v. 6, n. 2, \\
p. e2007, 16 out. 2020. DOI: \\
https://doi.org/10.35819/remat2020v6i2id4177
\end{tabular}

Histórico do Artigo

Submissão: 5 de maio de 2020.

Aceite: 6 de julho de 2020.

\section{Palavras-chave}

Geometria Analítica

Smartphone

Projeto Reforço Escolar

Aplicativo GeoGebra

Educação Matemática

\section{Resumo}

Esta pesquisa propõe apresentar uma sequência didática baseada em uma adaptação das dinâmicas do Projeto Reforço Escolar, da Secretaria Estadual de Educação do Estado do Rio de Janeiro em parceria com a Fundação Centro de Ciências e Educação Superior a Distância do Estado do Rio de Janeiro, utilizando o smartphone como ferramenta integrada na experimentação e avaliação do desempenho dos estudantes ao realizar as atividades propostas. Com o objetivo de construir um aprendizado mais concreto, dinâmico e interativo, foi utilizado o aplicativo GeoGebra. A pesquisa é de caráter quantitativo e qualitativo e os dados coletados buscaram investigar o desempenho e as reações dos estudantes em meio aos conceitos iniciais de Geometria Analítica. Pôde-se constatar por meio do experimento, que a sequência didática proposta, com a utilização integrada do smartphone, com adaptações das dinâmicas do Projeto Reforço Escolar auxiliada pelo aplicativo GeoGebra, contribuíram significativamente para a aprendizagem do tema proposto, favorecendo o conhecimento de uma forma mais atrativa, dinâmica e interativa.

\section{Abstract}

This research proposes to present a didactic sequence based on an adaptation of the dynamics of the School Reinforcement Project of the State Education Secretariat of the State of Rio de Janeiro in partnership with the Foundation Center for Sciences and Distance Higher Education of State of Rio de Janeiro, using the smartphone as an integrated tool in the performance of students when carrying out the proposed activities. In order to create a more concrete, dynamic and interactive learning, the GeoGebra App was used. This is quantitative and qualitative research and the data collected sought to investigate the performance and reactions of students amidst the initial concepts of Analytical Geometry. It was possible to verify through the experiment, that the proposed didactic sequence, with the integrated use of the smartphone, with School Reinforcement Project dynamics adaptations aided by the GeoGebra App, contributed significantly to the learning of the proposed theme, encouraging the knowledge in a more attractive, dynamic and interactive way. 


\section{Introdução}

Os estudantes, em sua maioria, apresentam grande dificuldade em Matemática, o que aumenta com o decorrer do avanço nas séries estudadas. Ela é uma das responsáveis pelo alto índice da reprovação escolar, na qual os alunos apresentam uma deficiência na aprendizagem. Segundo Druck (2005), a dificuldade em Matemática com o passar dos anos vai aumentando, pois os alunos no ensino fundamental não têm dúvidas sobre a utilidade do conteúdo estudado no seu cotidiano. O autor ainda afirma:

Ninguém pode se considerar verdadeiramente inserido na sociedade se não tiver alguma familiaridade com as quatro operações aritméticas, as frações, as unidades de medida e os conhecimentos básicos de Geometria. Ao nos aproximarmos do Ensino Médio, fica mais difícil identificar a utilidade imediata da Matemática (DRUCK, 2005, p. 3).

Sendo assim, é necessário repensar novas estratégias no processo de ensino aprendizagem da Matemática. Uma das estratégias é envolver o discente nesse processo como protagonista na construção do aprendizado, aliado a uma postura diferenciada do professor. Dessa forma, o docente não exercerá o papel de detentor do saber e sim o papel de mediador do conhecimento. Complementando essa mudança de postura em sala de aula, pode-se ainda associar o uso de tecnologias digitais. Sobre a autonomia do aluno, que deve ser incentivada pelo professor, Cunha, Oliveira e Ponte (1995, p. 23) afirmam:

$\mathrm{Na}$ disciplina de Matemática, como em qualquer outra disciplina escolar, o envolvimento ativo do aluno é uma condição fundamental da aprendizagem. O aluno aprende quando mobiliza os seus recursos cognitivos e afetivos com vista a atingir um objetivo. Esse é, precisamente, um dos aspectos fortes das investigações. Ao requerer a participação do aluno na formulação das questões a estudar, essa atividade tende a favorecer o seu envolvimento na aprendizagem.

Portanto, o papel do professor deixa de ser o de detentor da informação e de formação dos alunos e passa a ser visto de forma diferenciada. Não menos importante, ao contrário, pois vai intermediar a interação entre os alunos e o processo de construção do conhecimento (REGO, 2013).

Para Costa (2014), conseguir integrar o uso de novas tecnologias com os saberes, de forma a construir um ambiente de aprendizagem no qual esses recursos sejam potencializadores, e venham a promover uma aprendizagem interessante e significativa, é um grande desafio para os professores.

Contudo, o uso da tecnologia não deve ser feito somente como uma troca de quadro, giz, papel e caneta pelo computador ou celular, pois não significa que com a tecnologia digital o aluno passará a ter um aprendizado satisfatório. Recursos digitais podem facilitar o processo ensino e aprendizagem tanto para o estudante quanto para o professor. Para isso, faz-se necessário um bom plano de aula e uma sequência didática diferenciada.

Sobre o uso das tecnologias, D'AMBRÓSIO (2007, p. 74) diz:

A escola não se justifica pela apresentação de conhecimento obsoleto e ultrapassado e muitas vezes morto. Sobretudo ao se falar em ciência e tecnologia. 
Será essencial para a escola estimular a aquisição, a organização, a geração e a difusão do conhecimento vivo, integrado nos valores e nas expectativas da sociedade. Isso será impossível de atingir sem a ampla utilização de tecnologia na educação. Informática e comunicações dominarão a tecnologia educativa do futuro.

Com o intuito de facilitar o aprendizado e reconhecendo a importância que a tecnologia tem no processo de ensino-aprendizagem, esta pesquisa visa introduzir as tecnologias digitais no estudo da Geometria Analítica por meio do uso do aplicativo GeoGebra em smartphones. Além de associar o projeto Reforço Escolar da Secretaria Estadual de Educação do Rio de Janeiro/CECIERJ, que aborda questões investigativas direcionadas para a resolução de problemas, na qual o aluno constrói seus próprios planos e analisa seus resultados. O propósito é levar aos estudantes uma maneira interessante e atual de aprender um pouco mais sobre o tema, utilizando uma ferramenta tão constante e presente em seu dia a dia: o smartphone. Busca-se, assim, torná-lo um aliado de trabalho e não um concorrente, como ocorre em muitas aulas em que a atenção dos alunos fica completamente voltada para ele.

O estudo da Geometria Analítica possibilita a análise de propriedades e elementos geométricos por meio de processos algébricos. O aluno do Ensino Médio tem a oportunidade de pensar algebricamente sobre os problemas geométricos ou pensar geometricamente sobre problemas algébricos. Além disso, deve perceber que um mesmo problema matemático pode ser abordado com diferentes instrumentos pedagógicos de acordo com as suas características (BRASIL, 2002). Contudo, a defasagem no estudo da geometria e da álgebra em anos anteriores podem gerar sérias dificuldades no estudo da Geometria Analítica, o que desmotiva o aluno a prosseguir com o estudo e obter uma aprendizagem significativa.

A Geometria Analítica geralmente é trabalhada nos anos finais do Ensino Médio. No currículo mínimo, o conteúdo é apresentado no $3^{\circ}$ ano, e sugerido que se trabalhe nos $3^{\circ}$ e $4^{\circ}$ bimestres do ano letivo. Esta pesquisa foi realizada com uma turma do $3^{\circ}$ ano, do Colégio Estadual Luiz Reid, localizado no município de Macaé, no Estado do Rio de Janeiro. As atividades desenvolvidas foram adaptações das atividades do Projeto Reforço Escolar (CECIERJ, 2012), nas quais foram inseridas novas tecnologias na complementação deste material.

Por ser um aplicativo gratuito, amplamente utilizado em diversas áreas do ensino e por mostrar a representação algébrica e geométrica de um mesmo elemento, o aplicativo GeoGebra foi escolhido como instrumento auxiliar no aprendizado dos estudantes desta pesquisa.

Sobre o GeoGebra, Bastos (2014, p. 28) diz:

Acreditamos que o melhor software é o GeoGebra, para trabalhar com Geometria Analítica, pois além de ser gratuito e ter atualizações periódicas, o modo como ele relaciona geometria e álgebra é apropriado ao estudo da Geometria Analítica. A correspondência objeto-equação acontece em mão dupla. $O$ programa tanto permite esboçar gráficos a partir das equações, assim como define as equações do que é traçado geometricamente.

Entretanto este artigo traz a seguinte questão de pesquisa: como uma sequência didática fundamentada nas atividades do Projeto Reforço Escolar e integrada por recursos tecnológicos, 
podem facilitar o processo de ensino-aprendizagem dos conceitos iniciais de Geometria Analítica? Nesse contexto, o objetivo geral deste trabalho é avaliar o desempenho dos estudantes de uma turma do $3^{\circ}$ ano do Ensino Médio, através de uma experimentação adaptada nas dinâmicas do Projeto Reforço Escolar (CECIERJ, 2012) com a utilização do GeoGebra em smartphones.

Para atingir o objetivo geral desse trabalho, foram considerados os seguintes objetivos específicos: 1. Introduzir os recursos tecnológicos nas atividades investigativas do Projeto Reforço Escolar (CECIERJ, 2012); 2. Promover a compreensão dos conceitos iniciais de Geometria Analítica, em especial, Plano cartesiano, Distância entre pontos, Ponto médio e colinearidade, Equação da reta e Posições relativa entre as retas; 3. Analisar o impacto da experimentação no desempenho e na participação dos pesquisados, visando avaliar e aperfeiçoar a metodologia aplicada.

Por meio desses objetivos, espera-se que esta pesquisa sirva de suporte didáticopedagógico para profissionais da educação que desejam promover o senso de autonomia dos estudantes de maneira interativa, dinâmica e atraente, concentrada no envolvimento dele e no desenvolvimento do entendimento dos conceitos iniciais de Geometria Analítica.

Para atingir os objetivos gerais propostos nesta pesquisa, a experimentação didática foi totalmente envolvida numa metodologia ativa, imerso em um caráter quantitativo e qualitativo, com o uso integrado das tecnologias digitais. Através das análises da experimentação, percebeu-se que a sequência didática proposta contribuiu significativamente para o aprendizado dos conceitos iniciais de Geometria Analítica.

\section{Tecnologia Digitais de Informação e Comunicação na Educação e o Projeto Reforço Escolar}

As Tecnologias Digitais de Informação e Comunicação (TDIC) trazem mudanças principalmente no espaço escolar, gerando oportunidades para reflexões da formação docente e na adesão da tecnologia em meios a metodologias alternativas, com o propósito de tornar as práticas pedagógicas mais interessantes e atrativas, proporcionando aos alunos um ambiente onde ele poderá ter uma participação ativa na construção do seu conhecimento.

As mudanças são rápidas, profundas e silenciosas. Elas assinalam descontinuidades e o aparecimento de novos paradigmas. A educação não fica imune às novas condições sociais. O processo de globalização aponta para novas possibilidades de estar no mundo e para novas formas de ensinar e aprender (TOLEDO, 2003, p. 1).

Embora essa mudança e evolução das tecnologias venham ocorrendo, as escolas não estão acompanhando-as significativamente, pois o uso dessas ferramentas como recurso de ensino ainda é desconhecido por muitos estudantes e educadores. Os professores percebem a necessidade da inserção desses recursos na educação, mas por muitas vezes não sabem como fazê-lo, pois falta ser oferecido capacitação aos profissionais que o integrem a esse novo ambiente. 
Os PCN apontam a importância dos professores terem conhecimento sobre o uso das tecnologias como recurso para facilitar o processo de ensino e aprendizagem, pois caso contrário não é possível o auxílio de tais recursos. Isso, porém, não significa que os professores devam tornar-se especialistas, mas é necessário conhecer e saber utilizar as potencialidades das ferramentas em sala de aula (BRASIL, 2002).

O professor deve ter clareza sobre a escolha dos objetivos e da tecnologia a ser utilizada, e assim conseguir identificar se o aluno estará inserido de forma participativa no processo de aprendizagem e ainda se este será satisfatório. Para isso, é necessário que além da escolha adequada da tecnologia, o ambiente favoreça a participação, a interação e o compartilhamento de ideias, pois assim o estudante desempenhará um papel protagonista na construção do seu conhecimento.

A mudança pedagógica que todos almejam é a passagem de uma Educação totalmente baseada na transmissão da informação, na instrução, para a criação de ambientes de aprendizagem nos quais o aluno realiza atividades e constrói o seu conhecimento. Essa mudança acaba repercutindo em alterações na escola como um todo: na sua organização, na sala de aula, no papel do professor e dos alunos na relação com o conhecimento (VALENTE, 1996, p. 29).

A mudança educacional deve ocorrer e ela passa pela tecnologia, pois está inserida no cotidiano de todos, inclusive dos alunos, mas não se deve esquecer que o objetivo maior nessa busca é o de ensinar e educar. Ensinar com qualidade demanda um processo de mudança e renovação, e Moran, Masetto e Behrens (2000, p. 15) ponderam:

Nosso desafio maior é caminhar para um ensino e uma educação de qualidade, que integre todas as dimensões do ser humano. Para isso precisamos de pessoas que façam essa integração em si mesmas no que concerne aos aspectos sensorial, intelectual, emocional, ético e tecnológico, que transitem de forma fácil entre o pessoal e o social, que expressem nas suas palavras e ações que estão sempre evoluindo, mudando, avançando.

O uso da tecnologia não deve ser atribuído como uma ferramenta diferente de transmissão de conhecimento. E sim como um recurso que motive o aluno e também permita construir um conhecimento significativo, e não se torne apenas para repetição como nas aulas tradicionais. $A$ metodologia deve se adequar a uma forma em que o professor não seja o detentor da informação e assuma um papel de transmissor de conhecimentos e sim que promova a construção do conhecimento pelos próprios alunos, tornando-se assim, agente ativo e obtendo uma aprendizagem significativa. "[...] ensinar não é transferir conhecimento, mas criar as possibilidades para sua própria produção ou a sua construção" (FREIRE, 2016, p. 47).

O professor deixa de ser o transmissor de informações e passa a atuar como mediador, promotor, facilitador, desafiador e consultor. Cabe a ele criar uma situação de parceria e cooperação com os alunos e entre os alunos, considerar os assuntos emergentes no contexto, propor desafios ou eleger coletivamente um tema de estudo, questionar os alunos, convidá-los a verbalizar suas dificuldades e descobertas, provocar a formalização de conceitos e a tomada de consciência da evolução individual e grupal em relação às metas atingidas (ALMEIDA, 2008, p. 29). 
Para Costa (2014), quando o professor utiliza algum recurso tecnológico em sua aula como fim pedagógico, deve ser com a finalidade do uso de uma ferramenta de transmissão e construção do conhecimento. Com isso, a desmistificação da escola como um ambiente monótono ocorrerá e passará a ser visto como um ensino interessante, dinâmico e com o intuito de preparar seu aluno para o futuro, pois capacita o estudante para ser um usuário independente da informação.

Moran, Masetto e Behrens (2000, p. 143) ressaltam:

\begin{abstract}
Não se trata de simplesmente substituir o quadro negro e o giz por algumas transparências, por vezes tecnicamente mal elaboradas ou até maravilhosamente construídas num powerpoint, ou começar a usar um datashow. As técnicas precisam ser escolhidas de acordo com o que se pretende que os alunos aprendam. [...] Não podemos ter esperança de que uma ou duas técnicas, repetidas à exaustão, deem conta de incentivar e encaminhar toda a aprendizagem esperada.
\end{abstract}

Além de ser importante um bom planejamento e metodologia para inserir novas tecnologias digitais na educação, ela não deve ser motivada pelo fato de utilizar a tecnologia por moda ou simplesmente porque a escola vê a necessidade de estar atualizada com tais inovações, mas sim para facilitar a produção do conhecimento. E para isso, é fundamental que o professor tenha conhecimento e domínio das Tecnologias Digitais da Informação e Comunicação, pois são recursos pedagógicos riquíssimos, que podem vir a colaborar no processo ensino-aprendizagem quando o seu uso é feito de forma adequada.

Costa (2014) ressalta que, se as aulas se baseiam em métodos do passado, não basta utilizar recursos tecnológicos. O importante é utilizar as TDIC para reforçar conceitos, dinamizar e promover com mais ênfase o processo ensino aprendizagem. Assim, o uso das tecnologias em sala de aula, e especificamente nas aulas de Matemática, pode ser um grande aliado nesse processo. Para Costa (2014, p. 39):

Mesmo que a escola não ofereça subsídios para a inserção das novas tecnologias, o professor tem o dever, como agente de transformação e formador de opinião, de oferecer para seus educandos conhecimentos e interações com essas tecnologias, tendo em vista que fazem parte do cotidiano de muitos deles.

E é nesse sentido que esta pesquisa se apresenta. Mesmo com a ausência de uma sala de informática que atendesse a todos os alunos, ou ainda uma rede de internet que permitisse aos estudantes navegar na internet para fins educacionais, a tecnologia foi inserida nas aulas de Matemática, utilizando no dispositivo móvel (smartphone) de cada aluno o aplicativo GeoGebra. Dessa forma, ao oportunizar aos estudantes o acesso à informação e à construção do conhecimento, eles são motivados a aprender e se comprometer com a aprendizagem.

\title{
2.1. O smartphone como recurso pedagógico: aplicativo GeoGebra
}

A tecnologia está à disposição da humanidade e colabora para a sua evolução. Entretanto, quando se trata do espaço escolar, principalmente as unidades escolares públicas, o uso da tecnologia torna-se mais restrito por falta de um ambiente adequado, como laboratórios de informática. É nesse momento que o smartphone, hoje tão presente no cotidiano de quase toda a 
população, torna-se um aliado e um substituto dos computadores, para que seja possível a integração e utilização da tecnologia durante as aulas. Costa (2014, p. 93) diz: "O educador deve aproveitar as potencialidades do celular, como recurso pedagógico, tendo em vista que é uma realidade presente na vida de todos os educandos".

Os smartphones são telefones com tecnologia avançada, suportados por sistemas operacionais equivalentes aos computadores. Eles têm funções diversas, dentre as quais o uso de redes sociais, que facilita a comunicação em tempo real por meio de aplicativos como WhatsApp. $E$ ainda têm funcionalidades que podem auxiliar no processo educativo: registros pertinentes às aulas; assistir videoaulas que ajudem na assimilação do conteúdo; realização de pesquisas sobre o conteúdo trabalhado; utilização de aplicativos educativos que favoreçam e estimulem a aprendizagem, entre outras.

Com o uso do smartphone tão presente na vida dos alunos, é importante criar um ambiente transformador frente a essa tecnologia, para que a escola se atualize e construa assim, uma aprendizagem inovadora, dinâmica e motivadora, desenvolvendo nos alunos, estratégias investigativas que favoreçam o processo de ensino e aprendizagem.

Nesta pesquisa, o uso de smpartphones como ferramenta pedagógica foi feito e será apresentada a análise de como essa utilização pode ser benéfica ao ambiente de aprendizagem. Para isso, será considerado o aplicativo GeoGebra em todas as atividades.

O item explorado nesta pesquisa foi a Calculadora Gráfica GeoGebra, pois sua interface permite transformações com controles deslizantes, onde o usuário pode manipular a construção quando achar apropriado; a obtenção de pontos especiais de funções tais como as raízes, mínimos, máximos e as interseções, entre outras. A calculadora gráfica é interativa e dinâmica, ou seja, ela permite que o usuário exerça influência imediata sobre as construções geométricas, criando e fazendo animações quando for conveniente.

O aplicativo é uma ferramenta útil e completamente gratuito (desde a obtenção até o uso de todas as suas ferramentas). Para a utilização não há necessidade da internet, somente para fazer o download do aplicativo, sendo este um fato relevante nesta pesquisa.

Nesta perspectiva, esta pesquisa propõe-se à utilização dos smartphones com o aplicativo GeoGebra previamente instalados, para auxiliar nas resoluções das problematizações geradas pelo Projeto Reforço Escolar, visando uma experimentação única que tenciona o senso de autonomia do estudante. Vale ressaltar que este artigo não tem o intuito em discutir sobre o potencial do GeoGebra em relação ao estudo de Geometria Analítica, discussão já difundida e constatada em diversas pesquisas, por exemplo, Tenório, Souza e Tenório (2015); Guedes, (2015); entre outras; não obstante, o GeoGebra é utilizado nesta experimentação como uma ferramenta complementar, útil e importante para a difusão dos conceitos iniciais de Geometria Analítica. 


\subsection{O Projeto Reforço Escolar}

O Projeto Reforço Escolar realizado entre os anos de 2012 e 2015, pela Secretaria de Educação do Estado do Rio de Janeiro (SEEDUC) em parceria com a Fundação Centro de Ciências e Educação Superior a Distância do Estado do Rio de Janeiro (CECIERJ), tinha como objetivo, a melhoria da qualidade de ensino na rede estadual. O Reforço, a partir de CECIERJ (2012, p. 5), "Oportuniza a recuperação de aprendizagem, priorizando ações qualitativas na educação, com foco no Letramento em Leitura e Escrita e Letramento Matemático".

O Projeto foi destinado a alunos do $9^{\circ}$ ano do Ensino Fundamental e $1^{\circ}, 2^{\circ}$ e $3^{\circ}$ anos do Ensino Médio. O material didático foi organizado pela fundação CECIERJ e é composto de dinâmicas de Língua Portuguesa e Matemática. As dinâmicas foram organizadas para períodos de 100 minutos, o que contabiliza dois tempos de aula por semana.

Com o intuito de melhorar o desempenho acadêmico dos alunos, a Secretaria de Educação investiu no Projeto, de forma que eles eram atendidos em grupos menores e sempre no contraturno das aulas do ensino regular. O Projeto contava com professores qualificados e capacitados para conduzir as aulas.

O conteúdo das dinâmicas foi selecionado a partir do resultado das provas diagnósticas da SEEDUC, e foram tomadas as habilidades não desenvolvidas ou em desenvolvimento pelos estudantes. Os conteúdos contemplados foram os contidos no Currículo Mínimo. Os alunos selecionados para integrarem o Projeto eram, em geral, os que tinham baixo desempenho na prova Saerjinho, no qual o objetivo era avaliar o aprendizado bimestralmente, em Português e Matemática.

O Projeto Reforço Escolar foi desenvolvido e contava de maneira articulada com três frentes: o material didático, a formação e a estrutura. $O$ material didático produzido especificamente para uso do aluno e professores participantes. Aos professores foi oferecida a formação continuada a distância e presencialmente. E por fim a Estrutura, que foi a implementação e o acompanhamento das turmas no Projeto.

Todo o material desenvolvido era entregue às escolas participantes no formato com a versão para aluno e professor, como mostra a Figura 1.

Em CECIERJ (2012, p. 7), "A dinâmica do professor conta com orientações específicas e materiais complementares para apoiar o docente em sua prática pedagógica”.

As aulas ocorriam na Unidade Escolar em que o aluno estava matriculado e contava com duas aulas semanais para as disciplinas de Português e Matemática, no contraturno, durante os quatro bimestres. O uso do material didático oferecido pelo Projeto era obrigatório.

O principal diferencial nas dinâmicas é o papel que atribui aos alunos de protagonismo na construção do seu aprendizado. Esta pesquisa visa utilizar as dinâmicas do Projeto Reforço Escolar direcionadas para o ensino de Geometria Analítica e realizar as atividades no aplicativo GeoGebra. Dessa forma, as atividades do Projeto serão vistas não somente algebricamente no 
papel, como também graficamente no aplicativo, proporcionando aos alunos uma estratégia que desperte o seu interesse e seja motivadora, ao mesmo tempo que tenha uma ação eficiente na construção do seu conhecimento.

Figura 1 - Capa do material do Projeto Reforço Escolar.

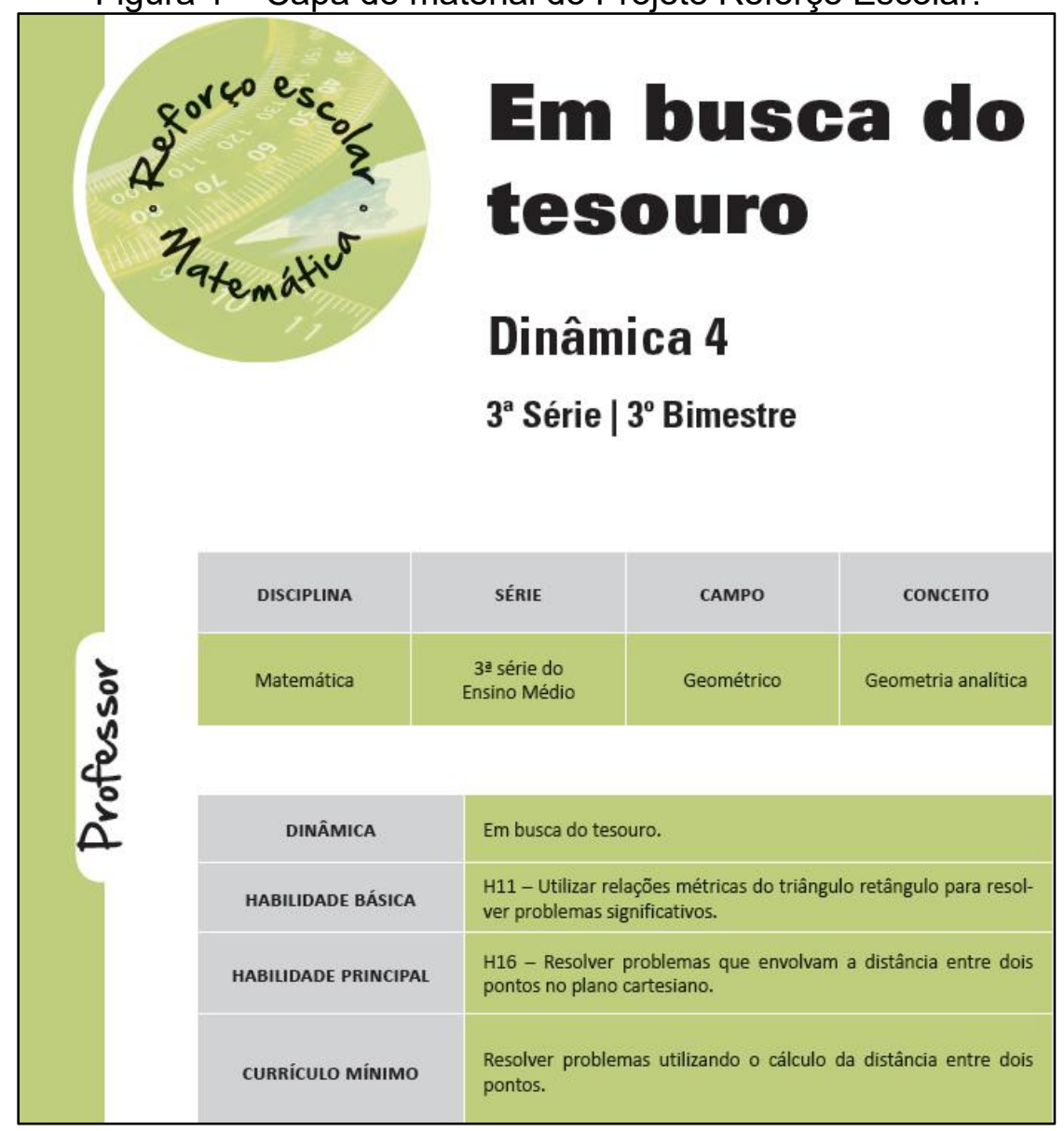

Fonte: CECIERJ (2012).

\section{Aspectos metodológicos}

Buscou-se com essa pesquisa investigar como uma sequência didática inspirada e adaptada do Projeto Reforço Escolar, com a utilização integrada das tecnologias, em especial o smartphone e o aplicativo GeoGebra, pode auxiliar no processo de ensino e aprendizagem dos conceitos de Geometria Analítica. A estrutura desta pesquisa considera as seguintes etapas: levantamento de perguntas e hipóteses; coleta de dados e análise e interpretação desses dados.

O propósito dessa pesquisa foi realizar uma experimentação exploratória, utilizando abordagens tanto quantitativa, no que concerne à quantificação dos resultados, quanto qualitativa, sendo esta por meio de intervenção pedagógica. Para Fonseca (2002, p. 20), "a pesquisa qualitativa se preocupa com aspectos da realidade que não podem ser quantificados, centrandose na compreensão e explicação da dinâmica das relações sociais".

A experimentação das atividades ocorreu no Colégio Estadual Luiz Reid localizado na cidade de Macaé, Estado do Rio de Janeiro, sendo aplicada nos meses de março a julho de 2019. 
O ano escolhido para experimentação das atividades foi $3^{\circ}$ ano do Ensino Médio, com 34 estudantes frequentando regularmente.

As etapas da pesquisa se dividiram em seis etapas: 1 - Coletas de Dados; 2 - Avaliação Diagnóstico; 3 - Aplicação da Sequência Didática (4 etapas); 4 - Análise dos dados. Detalhes mais específicos de todas as etapas da pesquisa podem ser vistos na íntegra na dissertação de Sant'Ana (2019).

\subsection{Coletas de dados e o teste diagnóstico}

Os instrumentos de coleta de dados utilizados nesta pesquisa foram as observações dos pesquisadores e registros das atividades dos estudantes. O teste diagnóstico, mais detalhes na dissertação de Sant'Ana (2019), foi aplicado com o objetivo de verificar quais conteúdos necessários ao desenvolvimento dessa pesquisa os alunos dominavam, e quais eles tinham mais dificuldade. Com o seu resultado pôde-se analisar e identificar as dificuldades mais significativas apresentadas, para então organizar o planejamento da sequência didática com os devidos ajustes para uma melhor abordagem do conteúdo de Geometria Analítica.

O teste diagnóstico foi elaborado com cinco questões. Cada uma das questões do teste contempla os seguintes conteúdos: (Plano Cartesiano, Geometria Básica, Proporcionalidade, Relação e Função afim), pré-requisitos necessários para o entendimento das etapas da pesquisa.

Por questões de acessibilidade, recomenda-se nesta pesquisa, que as questões do teste diagnóstico sigam modelos utilizados em livros didáticos do Ensino Médio que os estudantes tenham acesso, com suas devidas adaptações.

\subsection{Sequência didática}

Após análise do teste diagnóstico, foi elaborada a Sequência Didática (SD). Segundo Zabala (2015, p. 53), sequência didática é definida como "Um conjunto de atividades ordenadas, estruturadas e articuladas para realização de certos objetivos educacionais, que têm um princípio e um fim conhecidos tanto pelos professores quanto pelos alunos".

A SD foi estruturada de forma a seguir uma ordem em que os conteúdos são apresentados no currículo mínimo do Estado do Rio de Janeiro e também que seguissem uma ordem lógica de aprendizado, a fim de que os objetivos dessa pesquisa fossem alcançados. Um dos objetivos da sequência didática, segundo Zabala (2015, p. 54), é:

Introduzir nas diferentes formas de intervenção aquelas atividades que possibilitem uma melhora de nossa atuação nas aulas, como resultado de um conhecimento mais profundo das variáveis que intervêm e do papel que cada uma delas tem no processo de aprendizagem dos meninos e meninas.

As atividades da SD foram seguidas, após a aplicação do teste diagnóstico, pela aula expositiva utilizando recursos como datashow para apresentação do aplicativo GeoGebra e aulas introdutórias, todas presentes em Sant'Ana (2019). Todas as atividades têm como objetivo 
proporcionar ao aluno um conhecimento mais profundo do conteúdo estudado por meio das dinâmicas investigativas do Projeto Reforço Escolar, e através de intervenções pedagógicas concisas.

A experimentação é composta de quatro etapas, num total de 24 aulas de 40 minutos cada, como mostra o Quadro 1.

Quadro 1 - Descrições detalhadas das etapas da pesquisa.

\begin{tabular}{|c|c|c|}
\hline Etapas & Descrição das Atividades & $\begin{array}{l}\text { Duração (aulas } \\
\text { de 40min) }\end{array}$ \\
\hline $1^{a}$ & $\begin{array}{l}\text { - Diálogo com a turma sobre o objetivo da pesquisa; } \\
\text { - Aplicação do teste diagnóstico. }\end{array}$ & 2 aulas \\
\hline $2^{a}$ & $\begin{array}{l}\text { - Momento destinado ao compartilhamento da internet para os alunos que } \\
\text { não fizeram o download do aplicativo GeoGebra realizarem o download em } \\
\text { sala de aula; } \\
\text { - Criação do grupo no aplicativo Whatsapp para envio das atividades } \\
\text { realizadas pelos alunos no aplicativo GeoGebra; } \\
\text { - Apresentação de slides (SANT'ANA, 2019), mostrando as funcionalidades } \\
\text { da ferramenta GeoGebra; } \\
\text { - Atividades } 1 \text { e } 2 \text { - Adaptação da Dinâmica “Em Busca do Tesouro" - } \\
\text { Assuntos: Plano Cartesiano e Distância entre dois pontos. }\end{array}$ & 5 aulas \\
\hline $3^{a}$ & $\begin{array}{l}\text { - Aula sobre Ponto Médio e alinhamento de três pontos realizada no } \\
\text { datashow (SANT'ANA, 2019), com os alunos acompanhando os } \\
\text { procedimentos no aplicativo GeoGebra; } \\
\text { - Atividades } 3 \text { e } 4 \text { - Ponto médio e alinhamento de } 3 \text { pontos realizadas pelos } \\
\text { alunos através de seus smartphones com o auxílio do aplicativo GeoGebra. }\end{array}$ & 3 aulas \\
\hline $4^{a}$ & $\begin{array}{l}\text { - Apresentação de slides (SANT'ANA, 2019) tratando sobre a equação geral } \\
\text { da reta, no qual os alunos realizavam os procedimentos através do aplicativo } \\
\text { GeoGebra; } \\
\text { - Atividades 5, } 6 \text { e } 7 \text { - Adaptações das dinâmicas "Visita Virtual ao Museu" e } \\
\text { "Passeio pelo Rio". Assuntos: nessa etapa, os alunos construíram e } \\
\text { formalizaram alguns conceitos sobre as equações geral e reduzida da reta. }\end{array}$ & 10 aulas \\
\hline $5^{a}$ & $\begin{array}{l}\text { - Atividades } 8,9 \text { e } 10 \text { - Adaptação das dinâmicas "Tudo ou Nada" e "Ruas e } \\
\text { Esquinas". Assuntos: os alunos realizaram as atividades referentes a posição } \\
\text { relativa entre duas retas. }\end{array}$ & 6 aulas \\
\hline
\end{tabular}

Fonte: Dados da pesquisa (2019).

A SD assim como o objetivo, recomendação e dificuldades previstas de cada atividade estão detalhadas no Quadro 2. 
Quadro 2 - Descrição da Sequência Didática aplicada na pesquisa.

\begin{tabular}{|c|c|c|c|}
\hline Atividades & Objetivos & Recomendações & Dificuldades Previstas \\
\hline $\begin{array}{l}1 \text { - Pontos no plano } \\
\text { cartesiano e } \\
\text { distância entre dois } \\
\text { pontos. }\end{array}$ & $\begin{array}{l}\text { - Conhecer o plano } \\
\text { cartesiano; } \\
\text { - Compreender } \\
\text { através da } \\
\text { visualização a } \\
\text { distância entre dois } \\
\text { pontos; } \\
\text { - Concluir e aplicar a } \\
\text { "fórmula" da distância } \\
\text { entre dois pontos. }\end{array}$ & $\begin{array}{l}\text { - Deve ser realizada em dupla; } \\
\text { - Solicitar aos alunos que } \\
\text { façam, previamente, o } \\
\text { download do aplicativo } \\
\text { GeoGebra. } \\
\text { - O professor deve preparar } \\
\text { slides com as telas do } \\
\text { GeoGebra, a fim de apresentar } \\
\text { aos alunos o aplicativo, suas } \\
\text { funções e como manuseá-lo. }\end{array}$ & $\begin{array}{l}\text { - Embora em outro } \\
\text { momento já houvesse sido } \\
\text { solicitada a instalação do } \\
\text { aplicativo } \\
\text { GeoGebra,muitos alunos } \\
\text { não haviam feito no } \\
\text { primeiro momento. }\end{array}$ \\
\hline $\begin{array}{l}2 \text { - Distância entre } \\
\text { pontos. }\end{array}$ & $\begin{array}{l}\text { - Resolver situações } \\
\text { problemas aplicando } \\
\text { a distância entre } \\
\text { pontos. }\end{array}$ & $\begin{array}{l}\text { - Deve ser realizada em dupla; } \\
\text { - É necessário uma breve } \\
\text { revisão sobre o Teorema de } \\
\text { Pitágoras e sobre figuras } \\
\text { geométricas espaciais. }\end{array}$ & $\begin{array}{l}\text { - Os estudantes podem ter } \\
\text { dificuldades nos itens que } \\
\text { envolvem figuras } \\
\text { espaciais. }\end{array}$ \\
\hline $\begin{array}{l}3 \text { - Ponto médio e } \\
\text { condição de } \\
\text { alinhamento de } 3 \\
\text { pontos }-1^{\text {a }} \text { Parte. }\end{array}$ & $\begin{array}{l}\text { - Compreender o } \\
\text { conceito de ponto } \\
\text { médio; } \\
\text { - Compreender a } \\
\text { condição de } \\
\text { alinhamento de } 3 \\
\text { pontos } \\
\text { (Colinearidade). }\end{array}$ & $\begin{array}{l}\text { - Individual; } \\
\text { - A atividade é para organizar e } \\
\text { formalizar o conceito de ponto } \\
\text { médio e ainda visualizar } \\
\text { graficamente através do } \\
\text { aplicativo GeoGebra. É } \\
\text { importante que cada estudante } \\
\text { consiga realizar suas próprias } \\
\text { conclusões; } \\
\text { - O docente deve apresentar } \\
\text { todo o procedimento de } \\
\text { operacionalidade do aplicativo. }\end{array}$ & - Nenhuma. \\
\hline $\begin{array}{l}4 \text { - Ponto médio e } \\
\text { condição de } \\
\text { alinhamento de } 3 \\
\text { pontos }-2^{\mathrm{a}} \text { Parte. }\end{array}$ & $\begin{array}{l}\text { - Calcular o ponto } \\
\text { médio; } \\
\text { - Verificar } \\
\text { algebricamente a } \\
\text { colinearidade de } 3 \\
\text { pontos. }\end{array}$ & $\begin{array}{l}\text { - Individual; } \\
\text { - É recomendado revisar o } \\
\text { cálculo do determinante, pois a } \\
\text { atividade aborda questões que } \\
\text { envolve a condição de } \\
\text { colinearidade através do } \\
\text { determinante. }\end{array}$ & $\begin{array}{l}\text { - O discente pode não } \\
\text { recordar como se calcula o } \\
\text { determinante. }\end{array}$ \\
\hline $\begin{array}{c}5 \text { - Equação geral e } \\
\text { reduzida da reta - } \\
1^{\text {a }} \text { Parte. }\end{array}$ & $\begin{array}{l}\text { - Identificar e } \\
\text { determinar a } \\
\text { equação geral da } \\
\text { reta; } \\
\text { - Determinar a } \\
\text { equação reduzida da } \\
\text { reta. }\end{array}$ & $\begin{array}{l}\text { - Atividade em dupla; } \\
\text { - Aplicar o tutorial (SANT'ANA, } \\
\text { 2019) sobre a utilização do } \\
\text { aplicativo GeoGebra. }\end{array}$ & $\begin{array}{l}\text { - O estudante pode } \\
\text { apresentar dificuldade com } \\
\text { a manipulação algébrica. }\end{array}$ \\
\hline $\begin{array}{c}6 \text { - Equação geral e } \\
\text { reduzida da reta - } \\
2^{a} \text { Parte. }\end{array}$ & $\begin{array}{l}\text { - Analisar os } \\
\text { coeficientes da } \\
\text { equação reduzida; } \\
\text { - Identificar e } \\
\text { determinar a } \\
\text { equação de uma reta } \\
\text { a partir de sua } \\
\text { inclinação. }\end{array}$ & $\begin{array}{l}\text { - Atividade em dupla; } \\
\text { - Revisar o conceito de círculo } \\
\text { trigonométrico; } \\
\text { - Deve-se fazer a correção e } \\
\text { discussão da atividade final. }\end{array}$ & $\begin{array}{l}\text { - Manipulações } \\
\text { algébricas; } \\
\text { - Falta de conhecimento } \\
\text { sobre o ciclo } \\
\text { trigonométrico e } \\
\text { propriedades. }\end{array}$ \\
\hline $\begin{array}{c}7 \text { - Equação geral e } \\
\text { reduzida da reta - } \\
\text { Gincana. }\end{array}$ & $\begin{array}{l}\text { - Revisar e reforçar } \\
\text { todo o conteúdo } \\
\text { sobre a equação da } \\
\text { reta; } \\
\text { - Construção geral } \\
\text { da equação da reta; } \\
\text { - Analisar a } \\
\text { intersecção de duas } \\
\text { retas; }\end{array}$ & $\begin{array}{l}\text { - Atividade em grupo de } 5 \\
\text { estudantes; } \\
\text { - O professor não deverá } \\
\text { interferir na discussão do } \\
\text { grupo; } \\
\text { - Um integrante do grupo } \\
\text { deverá apresentar a solução } \\
\text { para os demais. }\end{array}$ & $\begin{array}{l}\text { - Manipulações } \\
\text { algébricas; } \\
\text { - Alguns estudantes } \\
\text { podem apresentar } \\
\text { dificuldades em trabalhar } \\
\text { em equipe. }\end{array}$ \\
\hline
\end{tabular}




\begin{tabular}{|c|c|c|c|}
\hline & $\begin{array}{l}\text { - Analisar e } \\
\text { determinar } \\
\text { inclinações da reta. }\end{array}$ & & \\
\hline $\begin{array}{c}8 \text { - Posição relativa } \\
\text { entre duas retas - } \\
1^{\text {a }} \text { Parte. }\end{array}$ & $\begin{array}{l}\text { - Identificar retas } \\
\text { paralelas } \\
\text { graficamente a partir } \\
\text { da análise de seus } \\
\text { coeficientes } \\
\text { angulares. } \\
\end{array}$ & $\begin{array}{l}\text { - Atividade em dupla; } \\
\text { - Os estudantes devem estar } \\
\text { com o aplicativo GeoGebra } \\
\text { instalados em seus } \\
\text { smartphones. }\end{array}$ & - Nenhuma. \\
\hline $\begin{array}{c}9 \text { - Posição relativa } \\
\text { entre duas retas - } \\
2^{\mathrm{a}} \text { Parte. }\end{array}$ & $\begin{array}{l}\text { - Analisar e } \\
\text { identificar a posição } \\
\text { relativa entre retas a } \\
\text { partir de suas } \\
\text { equações na forma } \\
\text { geral. } \\
\end{array}$ & $\begin{array}{l}\text { - Atividade em dupla; } \\
\text { - Os estudantes devem estar } \\
\text { com o aplicativo GeoGebra } \\
\text { instalados em seus } \\
\text { smartphones. }\end{array}$ & $\begin{array}{l}\text { - Manipulações } \\
\text { algébricas; }\end{array}$ \\
\hline $\begin{array}{l}10 \text { - Posição } \\
\text { relativa entre retas } \\
\text { concorrentes e } \\
\text { perpendiculares. }\end{array}$ & $\begin{array}{l}\text { - Analisar e } \\
\text { identificar a posição } \\
\text { relativa entre retas a } \\
\text { partir de suas } \\
\text { equações na forma } \\
\text { geral. }\end{array}$ & $\begin{array}{l}\text { - Atividade em dupla; } \\
\text { - Os estudantes devem estar } \\
\text { com o aplicativo GeoGebra } \\
\text { instalados em seus } \\
\text { smartphones. }\end{array}$ & $\begin{array}{l}\text { - Os alunos podem } \\
\text { apresentar dificuldades em } \\
\text { analisar o coeficiente } \\
\text { angular das retas paralelas } \\
\text { aos eixos coordenados. }\end{array}$ \\
\hline
\end{tabular}

Fonte: Dados da pesquisa (2019).

A Atividade 2, por exemplo, utiliza na íntegra a dinâmica "Em Busca do Tesouro" do Projeto Reforço Escolar, adaptado com a utilização do aplicativo GeoGebra. Nesta dinâmica, buscou-se avaliar os pesquisados através dos registros das atividades nas habilidades básica e principal. Na habilidade básica, foi avaliada a utilização métrica adequada do triângulo retângulo para a resolução de problemas significativos, e na habilidade principal, foram avaliadas a análise, interpretação e resolução dos problemas que envolvem a distância entre pontos no plano cartesiano. A Figura 2 apresenta as questões 1 e 3 da Atividade 2.

Figura 2 - Atividade 2: Questão 1 (à esquerda) e Questão 2 (à direita).

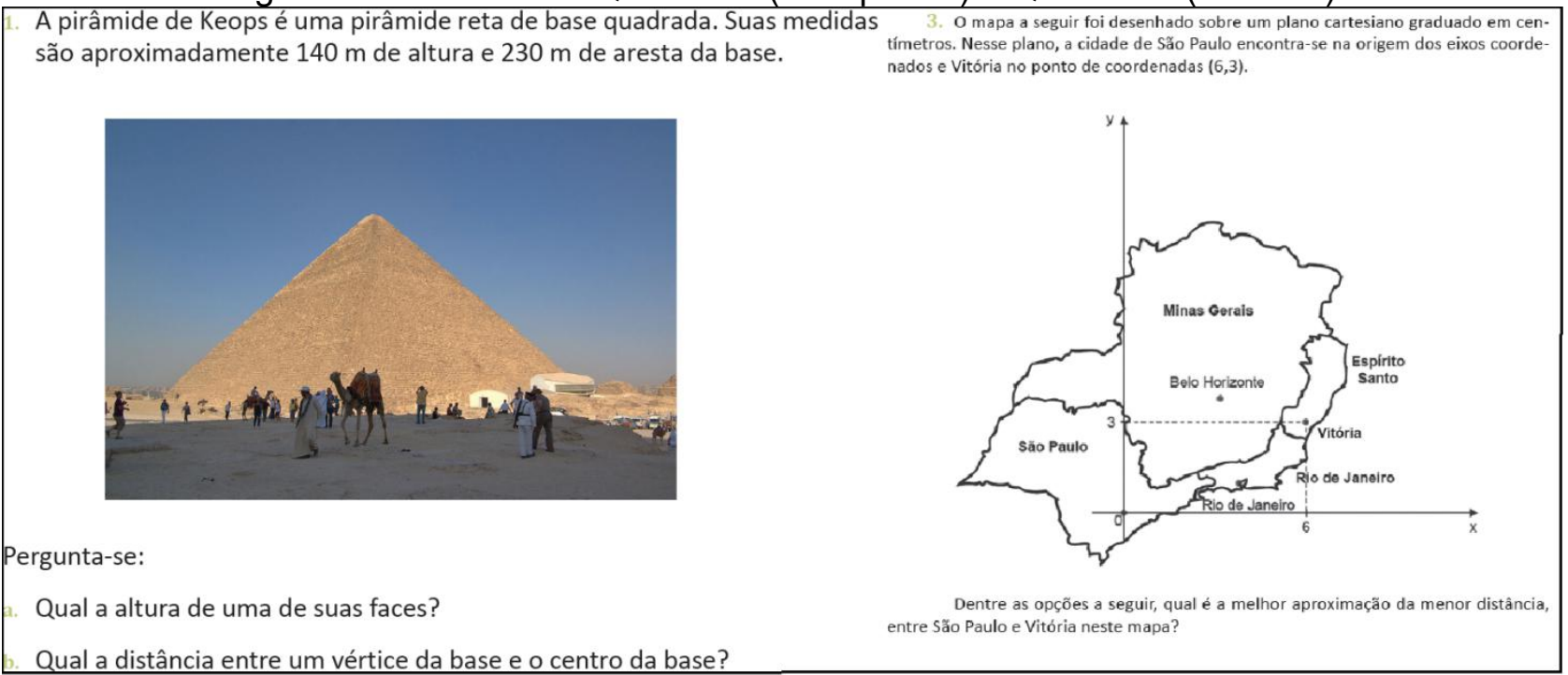

Fonte: CECIERJ (2012).

Também foi avaliado através da observação e registros dos estudantes, se a integração do aplicativo GeoGebra nas atividades, contribuiu para o desenvolvimento cognitivo dos pesquisados frente aos conceitos iniciais de Geometria Analítica. 


\section{Resultados e experimentação da Sequência Didática}

Neste artigo será feita uma breve descrição sobre a experimentação da sequência didática, em uma abordagem qualitativa, com destaque para as percepções dos estudantes, as intervenções pedagógicas e algumas conclusões. Devido à dimensão deste artigo, serão apresentadas análises sucintas das três últimas atividades, para as quais foi imprescindível a utilização do smartphone. As análises mais detalhadas estão presentes na dissertação de Sant'Ana (2019).

\subsection{Análise do Teste Diagnóstico}

No Gráfico 1, é apresentado o desempenho dos pesquisados em relação ao teste Diagnóstico. Na dissertação de Sant'Ana (2019) pode-se ver análises pontuais para cada questão do teste.

\section{Gráfico 1 - Resultados quantitativos do Teste Diagnóstico.}

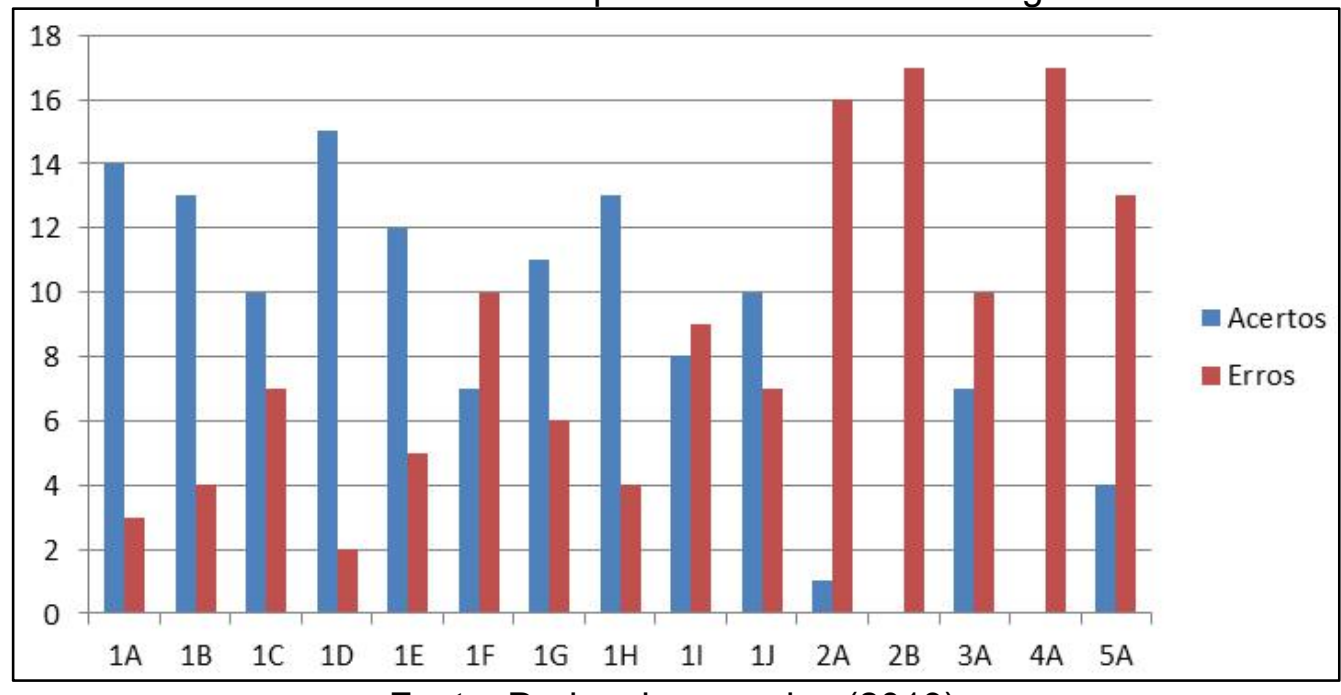

Fonte: Dados da pesquisa (2019).

Após a análise dos registros dos estudantes, chegou-se às seguintes constatações, que merecem atenção na pesquisa:

- A maioria dos estudantes desconhece conceitos básicos da geometria plana;

- Grande parte dos pesquisados apresentou dificuldades em resolver questões que envolvem os conceitos e propriedades da trigonometria;

- Parte considerável dos pesquisados não apresentou familiaridade na construção da função afim.

O conhecimento ao mínimo superficial dos conceitos mencionados acima são de elevada importância para o estudo mais amplo de Geometria Analítica. Este fato despertou na pesquisa a preocupação em introduzir na SD, revisões específicas antes das aplicações, como apresentou o Quadro 1. 


\subsection{Análise das atividades}

O Gráfico 2 apresenta os resultados numéricos comparando o desempenho dos pesquisados na Atividade 1 e as últimas Atividades 8, 9 e 10. São notórios a evolução e o desempenho satisfatório dos estudantes no decorrer da SD. Imersos numa tecnologia integrada com atividades bem formuladas do Projeto Reforço Escolar, os pesquisados apresentaram avanços consideráveis no decorrer do experimento, promovendo de forma eficaz o conhecimento nos conceitos básicos de Geometria Analítica.

Gráfico 2 - Evolução quantitativa de Acertos e Erros das Atividades propostas.

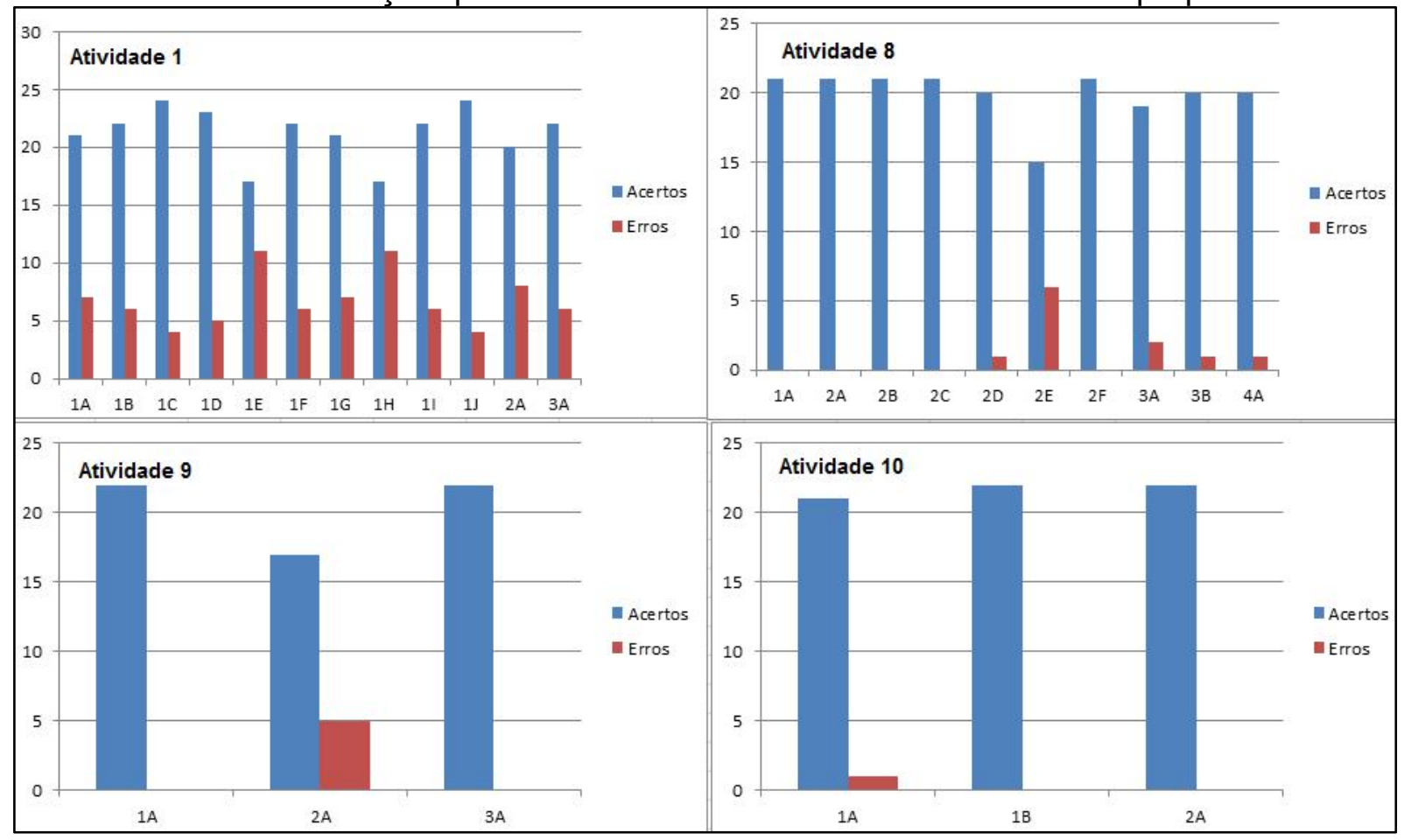

Fonte: Dados da pesquisa (2019).

A Figura 3 apresenta a primeira questão da Atividade 8. A habilidade principal desta atividade é a identificação das retas paralelas a partir das suas equações. É esperado que os estudantes concluam através das construções geométricas com auxílio do GeoGebra, a relação dos coeficientes angulares entre retas paralelas. Nesse estágio da experimentação, todos os sujeitos da pesquisa já tinham familiaridade com o aplicativo GeoGebra. Por meio da observação e registros, pôde perceber nesta pesquisa que o aplicativo foi fundamental para um aprendizado reflexivo, onde coube apenas o estudante ser protagonista do seu próprio aprendizado. Mesmo com dificuldades no estudo da função afim, diagnosticado no pré-teste, os estudantes conseguiram gerar reflexões construtivas e coerentes sobre o posicionamento das retas, resolucionando o problema.

Estes resultados corroboram com os estudos de Tenório, Souza e Tenório (2015, p. 103), no qual afirmam:

Manusear o software promoveu interesse, participação e interação, além de desenvolver a autonomia. Na visão dos alunos, o software foi importante na 
aprendizagem por ajudar no entendimento, complementar as explicações do professor e dinamizar as aulas. A principal vantagem do GeoGebra no estudo de Geometria Analítica foi estabelecer uma ponte entre álgebra e geometria, ao possibilitar a observação simultânea de expressões algébricas e suas representações gráficas.

Figura 3 - Primeira questão da Atividade 8 (primeira etapa).

\section{Privienra Etapa}

\section{Compartilhar ideias}

\section{Atividade 。 Haverá encontro?}

\section{Questão 1:}

Numa caminhada pela Via Lagos, dois estudantes decidiram medir a distâncias que cada um percorreria, a partir do ponto inicial da via. $O$ tempo t seria contado a partir de um instante em que ambos já tivessem atingido a velocidade de percurso que seria mantida por algum tempo. Fred percebeu que, enquanto mantivesse essa velocidade, a distância ao ponto inicial podia ser descrita pela equação:

$$
s=5 t+0,7 \text {. }
$$

Já seu amigo Hulk identificou que a equação relativa à sua caminhada nesse mesmo intervalo era:

$$
s=5 t+1,2 \text {, }
$$

onde s é dada em kilômetros e t em horas.

Pergunta:

Será que Fred e Hulk se encontraram nesse intervalo de tempo? Justifique sua resposta, esboçando no mesmo sistema de coordenadas o gráfico de $s$ em função de $t$, definida em cada uma dessas equacões.

$$
\text { Fonte: CECIERJ (2012). }
$$

Os estudantes puderam explorar a dinamização do aplicativo. Como se pode ver na Figura 4, os pesquisados geraram construções de retas utilizando como auxílio o controle deslizante, tornando a construção mais interativa e reflexiva.

Figura 4 - Utilização do controle deslizante na verificação de retas paralelas.

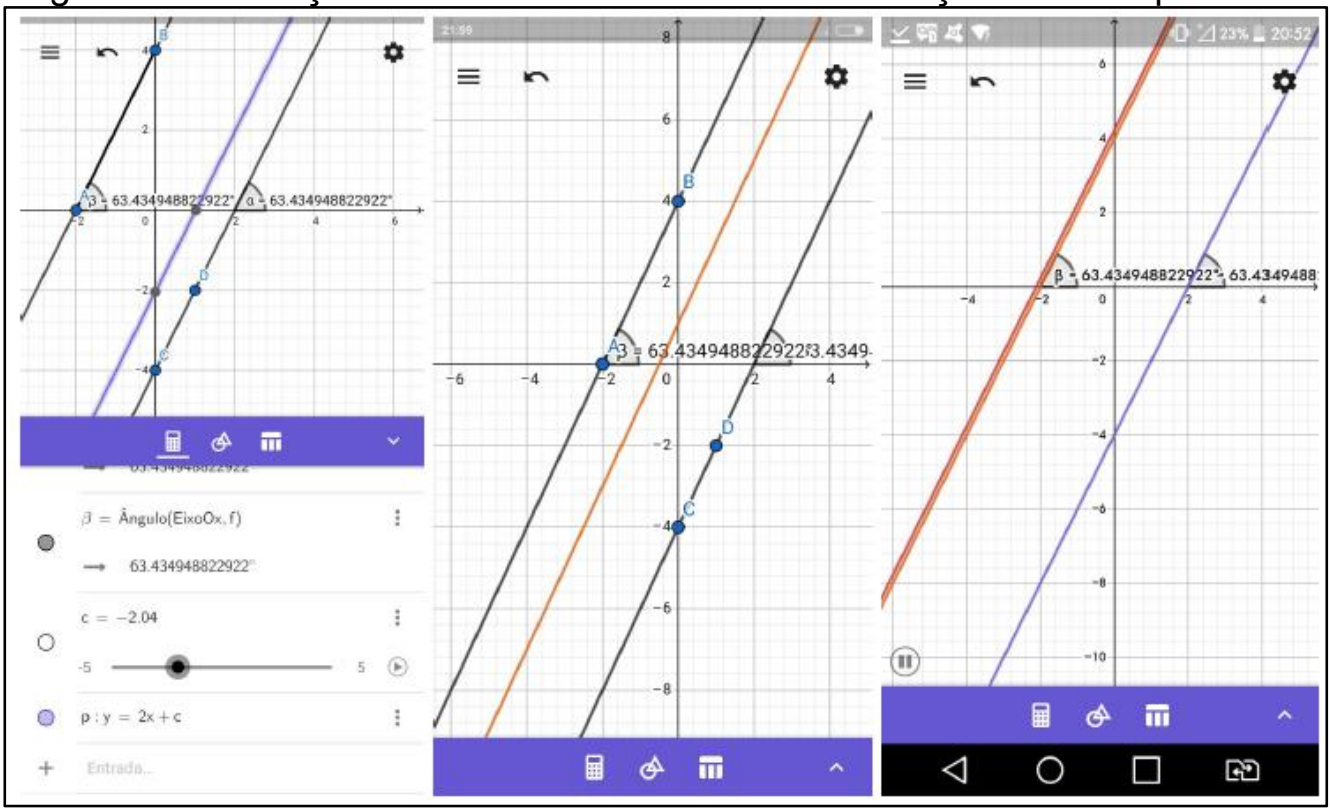

Fonte: Dados da pesquisa (2019). 
Nas Atividades 9 e 10, os pesquisados tiveram uma excelente avaliação. Todos se mostraram seguros e a maioria obtivera êxito nas construções e resoluções das questões propostas. Na Atividade 9, todos os envolvidos na pesquisa conseguiram escrever e construir as equações reduzidas e a condição de paralelismo, analisando os coeficientes angulares, entretanto, alguns estudantes tiveram dificuldades para concluir a análise do coeficiente linear. Para estes estudantes foram necessárias intervenções pedagógicas pontuais, juntamente com o auxílio do aplicativo, com o objetivo de possibilitar aos pesquisados que compreendam o conteúdo desenvolvido por meio da reflexão da sua própria construção. As intervenções geraram argumentos do tipo: "Então quer dizer que o coeficiente angular é o que inclina a reta?"; "Há entendi, o coeficiente linear é onde corta o eixo y." ou "Olha!! O valor que multiplica x é a tangente do ângulo que inclina a reta".

A Figura 5 apresenta a primeira questão da Atividade 10. Nesta questão foram solicitados as construções no aplicativo e a identificação das retas que atendem às exigências de "Badu". A fim de manter o tema urbano, essas retas foram expostas como retas suporte de ruas de um mapa cartesiano. A questão prossegue analisando a relação entre as tangentes trigonométricas para, então, chegar nas condições de perpendicularismo sobre os coeficientes angulares. É esperado que os estudantes consigam deduzir os resultados teóricos com autonomia e concluam através das construções geométricas com auxílio do GeoGebra, a relação dos coeficientes angulares entre retas perpendiculares.

Figura 5 - Primeira questão da Atividade 8 (segunda etapa).

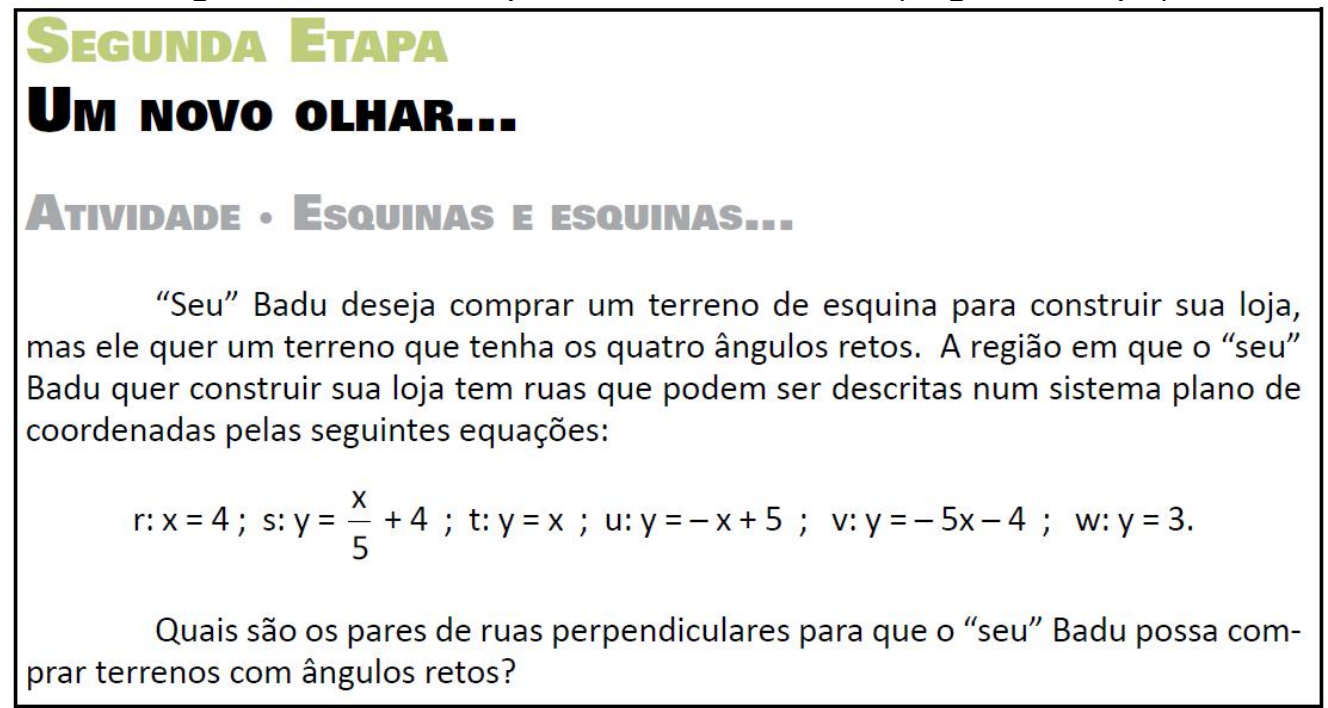

Fonte: CECIERJ (2012).

Entretanto os estudantes tiveram dificuldades em perceber que as retas do tipo $r_{1}: y=a$ ou $r_{2}: x=b$, para $a$ e $b$ constantes pertencentes aos reais, são retas perpendiculares aos eixos coordenados. Entretanto, com intervenções pedagógicas pontuais auxiliadas pelo aplicativo GeoGebra, os estudantes compreenderam essa particularidade, se mostrando mais seguros e 
familiarizados com retas dessa natureza. A Figura 6 mostra a construção das retas que um determinado estudante realizou no aplicativo, juntamente com os ângulos formados entre as retas.

Figura 6 - Construção de retas perpendiculares relativo à questão 1 da Atividade 10.

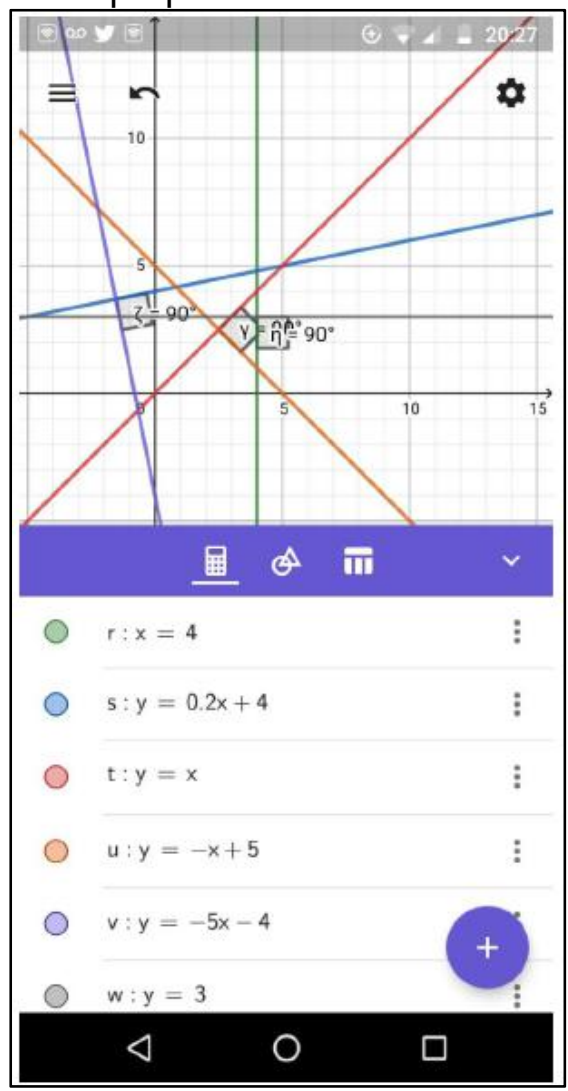

Fonte: Dados da pesquisa (2019).

Após as construções no aplicativo, geraram argumentos do tipo: "Interessante...os coeficientes angulares das retas perpendiculares são inversos um do outro com sinal trocado". A Figura 7 apresenta um registro do estudante chegando a essa conclusão.

Figura 7 - Registro discente relativo à questão 1 da Atividade 10

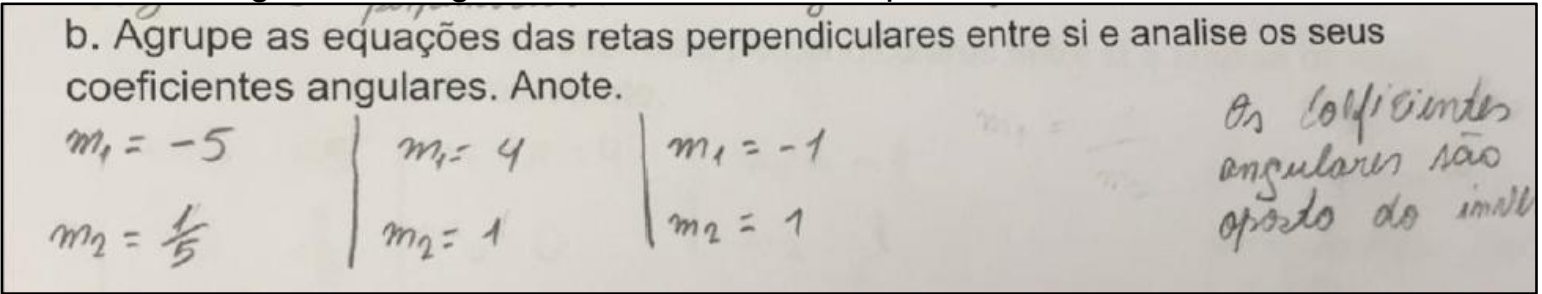

Fonte: Dados da pesquisa (2019).

Diante do exposto, conclui-se que os resultados foram satisfatórios, pois a utilização do apilcativo GeoGebra em smartphones, tornou a SD mais interessante, interativa e agradável, além de ter contribuído para que os estudantes fossem protagonistas nos processos de ensino e aprendizagem. Segundo Freire (2016), ensinar não é transferir conhecimento, mas criar condições para a sua construção. Valente (1999, p. 29) corrobora:

A mudança pedagógica que todos almejam é a passagem de uma educação totalmente baseada na transmissão da informação, na instrução, para a criação de 
ambientes de aprendizagem nos quais o aluno realiza atividades e constrói o seu conhecimento.

A análise dos dados levantados, das justificativas, intervenções pedagógicas e dos registros das atividades, permitiu confirmar as vantagens da experimentação didática proposta juntamente com a adaptação do Projeto Reforço Escolar e a utilização do aplicativo GeoGebra em smartphones. Além disso, foi possível constatar que a sequência didática integrada com a tecnologia juntamente com à intervenção dos pesquisadores contribuiu para a construção do conhecimento sobre os conceitos iniciais de Geometria Analítica.

\section{Considerações finais}

A presente pesquisa propôs uma experimentação didática sobre tópicos introdutórios da Geometria Analítica para o $3^{\circ}$ ano do Ensino Médio, utilizando as Tecnologias Digitais da Informação e Comunicação, as TDIC, por meio do aplicativo GeoGebra para smartphones, associado as dinâmicas do Projeto Reforço Escolar do Estado do Rio de Janeiro/CECIERJ.

Por meio da pesquisa bibliográfica e pesquisa aplicada, pode-se perceber o quanto a inserção das TDIC em sala de aula é importante. Mesmo que não seja simples, pois requer um planejamento de aula que atenda as necessidades do aluno e do professor. O uso da tecnologia associado a resolução das questões do Projeto Reforço Escolar, levou o aluno a desempenhar um papel ativo na construção do seu conhecimento. E ao professor, um papel de facilitador do acesso a essa aprendizagem.

Com base nessas constatações, foi apresentada uma sequência de atividades que abordam os conteúdos de Geometria Analítica, no qual o aluno teve a oportunidade de participar ativamente da construção do conhecimento utilizando o aplicativo GeoGebra. O uso do aplicativo foi de fundamental importância, pois possibilitou a visualização geométrica dos elementos algébricos, facilitando a formalização e conceituação dos conteúdos. Com base na análise das resoluções das atividades, nas observações feitas durante a aplicação das atividades e nas respostas orais e escritas dos pesquisados, observou-se que a dificuldade mais frequente foi as manipulações algébricas.

Respondendo a questão de pesquisa, foi constatado que a experimentação didática com o uso integrado das TDIC, baseado nas adaptações das dinâmicas do Projeto Reforço Escolar, pode sim, contribuir significativamente para o ensino dos conceitos iniciais de Geometria Analítica para estudantes do $3^{\circ}$ ano do Ensino Médio.

Como contribuições futuras, pretende-se avançar os conteúdos da SD, como o estudo das cônicas, visando explorar a animação ou outras potencialidades do aplicativo GeoGebra não utilizados nesta pesquisa.

Em síntese, espera-se que esta pesquisa sirva de suporte didático-pedagógico para os professores da área de Matemática que desejam ter uma práxis inovadora e, por meio desta, promover a mudança do cenário atual da educação brasileira. 


\section{Referências}

ALMEIDA, M. E. B. de. Tecnologia na escola: criação de redes de conhecimentos. 18 jul. 2008.

Disponível em : http://penta3.ufrgs.br/MEC-

CicloAvan/integracao midias/modulos/1 introdutorio/pdf/texto Tecnologia escola.pdf. Acesso em:

14 ago. 2020.

BASTOS, D. de O. Estudo da circunferência no Ensino Médio: sugestões de atividades com a utilização do software GeoGebra. 2014, 199 f. Dissertação (Mestrado Profissional em Matemática em Rede Nacional) - Universidade Federal do Rio Grande, Rio Grande, 2014.

BRASIL. Ministério da Educação. Secretaria de Educação Média e Tecnológica. Parâmetros Curriculares Nacionais: Ciências da Natureza, Matemática e suas Tecnologias. Brasília: MEC, SEMTEC, 2002.

CECIERJ, F. Projeto Reforço Escolar: manual. 2012. Disponível em: http://projetoseeduc.cecierj.edu.br/reforco-escolar.php. Acesso em: 14 ago. 2020.

COSTA, I. Novas tecnologias e aprendizagem. 2. ed. Rio de Janeiro: Wak, 2014.

CUNHA, H.; OLIVEIRA, H.; PONTE, J. P. da. Investigações matemáticas na sala de aula. Actas do ProfMat. Lisboa: APM, p.161-167, 1995.

D’AMBRÓSIO, U. Educação Matemática: da teoria à prática. 16. ed. Campinas: Papirus, 2007.

DRUCK, S. Matemática não é problema. Boletim 06, Campina Grande, p. 3-8, mai. 2005.

Disponível em: http://pibidmatematicaces.files.wordpress.com/2013/10/livro-de-matemc3a1tica.pdf.

Acesso em: 14 ago. 2020.

FONSECA, J. J. S. Metodologia da pesquisa científica. Fortaleza: Universidade Estadual do Ceará, 2002. Disponível em: http://www.ia.ufrrj.br/ppgea/conteudo/conteudo-2012-

1/1SF/Sandra/apostilaMetodologia.pdf. Acesso em: 14 ago. 2020.

FREIRE, P. Pedagogia da autonomia: saberes necessários à prática educativa. 53. ed. Rio de Janeiro: Paz e Terra, 2016.

GUEDES, P. C. C. Aplicação do software GeoGebra ao ensino da Geometria Analítica. Revista Ciência e Natura, Santa Maria, v. 37, edição especial PROFMAT, p. 365-375, 2015. DOI:

http://dx.doi.org/10.5902/2179460X14555.

MORAN, J. M.; MASETTO, M. T.; BEHRENS, M. A. Novas tecnologias e mediação pedagógica. 10. ed. Campinas: Papirus, 2000.

REGO, T. C. Vygotsky: uma perspectiva histórico-cultural da educação. Petrópolis: Vozes, 2013.

SANT'ANA, E. da C. Estratégia Didática para o Ensino de Geometria Analítica com o auxílio do Aplicativo GeoGebra. 2019. 161 f. Dissertação (Mestrado em Matemática) - Programa de Pós-Graduação Profissional em Matemática, Universidade Estadual do Norte Fluminense Darcy Ribeiro, Campos dos Goytacazes, RJ, 2019.

TENÓRIO, A.; SOUZA, S. M. R. de; TENÓRIO, T. O uso do software GeoGebra no estudo de Geometria Analítica. Revista do Instituto GeoGebra de São Paulo, São Paulo, v. 4, n. 2, p. 103121, 2015. Disponível em: http://revistas.pucsp.br/IGISP/article/view/24003. Acesso em: 14 ago. 2020. 
TOLEDO, F. S. Texto e contexto da educação a distância. 2003. Disponível em: http://www.lo.unisal.br/nova/aed/artigo1.html. Acesso em: 30 dez. 2017.

VALENTE, J. A. O Professor no Ambiente Logo: Formação e Atuação. 1. ed. Campinas: Gráfica da UNICAMP, 1996.

VALENTE, J. A. Mudanças na sociedade, mudanças na educação: o fazer e o compreender. In: VALENTE, José Armando (Org.). O computador na sociedade do conhecimento. Campinas: NIED-UNICAMP, 1999.

ZABALA, A. A prática educativa: como ensinar. 1. ed. Porto Alegre: Artmed, 2015. 